\title{
Optimization of Suitable Electrolyte for High Emittance coating on Titanium Alloy
}

\author{
Deepa $\mathrm{H} \mathrm{A}^{1 *}$, Poornitha $\mathrm{S}^{2^{*}}$, Akansha Soni ${ }^{3 *}$, Adil Hamza ${ }^{*}$ \\ "Department of Chemical Engineering, DSCE, Bengaluru, India \\ Corresponding author: *Deepa H A
}

\begin{abstract}
Titanium and it's alloys are used in the aerospace industry due to its light weigh, strength and ability to withstand extreme temperatures. Also titanium is as strong as Steel but much lighter, it is twice as strong as aluminum. It is nearly as resistant to corrosion as platinum. Titanium is used in dental implants due to its ability to Osseo integrate (an unusual ability by which titanium fuses with bone tissue through the titanium oxide layer on titanium metal). Titanium dioxide is relatively clear and has an extremely high index of refraction with an optical dispersion higher than diamond. Titanium dioxide is used extensively for paints as it is permanent and has good covering power. The present work involves optimization of the electrolyte composition in order to get a coating with high emissivity on titanium alloy using micro arc oxidation process. It also involves study of other parameters such as Thermo-optical properties, surface and characterization of the coating.
\end{abstract}

Keywords: Emissivity, Micro arc oxidation, Surface Coating, Thermo-optical property, Electro-chemical oxidation

\section{INTRODUCTION}

Controlling the level of temperature of equipment, payloads, satellites and launchers is essential during all phases of a space mission. Thermal control allows the maintenance of satellite's temperature within set parameters during its lifetime. Physical integrity of the satellites and its efficient operation is absolutely essential, because electronic equipment have their optimum performance within a certain temperature range. The satellite's payload will dictate its operating range by the balance prevailing between incoming external solar, albedo, planet heat fluxes and heat produced internally. The thermal control subsystems seek to maintain the overall temperature to an acceptable level and also to obtain the most adequate temperature distribution within the satellite. A thermal engineer ensures proper designing and management of heat distribution within the satellite. The present work gives the details of development of thermal control coating obtained using Titanium alloy substrate by micro arc oxidation technique and optimization of suitable electrolyte.

\section{OBJECTIVES:}

The objectives of the project are:

- To optimize electrolyte composition for obtaining high emissive oxide coating on titanium alloy using micro arc oxidation.
- To study the effect of various process parameters on coating characterization.

\section{LITERATURE SURVEY:}

Similar works are carried out by various researchers. Few of them are listed below:

1. 'Micro-arc oxidation of $\mathrm{Ti}_{6} \mathrm{Al}_{4} \mathrm{~V}$ and $\mathrm{Ti}_{6} \mathrm{Al}_{7} \mathrm{Nb}$ alloys for biomedical applications' worked by Huseyin et al [1]. In the study, the in-vitro biological responses of two competitive titanium alloys $\left(\mathrm{Ti}_{6} \mathrm{Al}_{4} \mathrm{~V}\right.$ and $\mathrm{Ti}_{6} \mathrm{Al} 7 \mathrm{Nb}$ ) were investigated after modifying their surfaces by the micro-arc oxidation (MAO) process conducted in a $\left(\mathrm{CH}_{3} \mathrm{COO}\right)_{2} \mathrm{Ca} \cdot \mathrm{H}_{2} \mathrm{O}$ and $\mathrm{Na}_{3} \mathrm{PO}_{4}$ containing electrolyte under identical electrical parameters and exposure time. After the process, the surfaces of the alloys were covered with a thick (approx. $10 \mu \mathrm{m}$ ) $\mathrm{TiO}_{2}$ layer exhibiting different characteristics. The oxide layer of the $\mathrm{Ti}_{6} \mathrm{Al}_{4} \mathrm{~V}$ alloy was porous and contained hydroxyapatite precipitates whereas the oxide layer of the $\mathrm{Ti}_{6} \mathrm{Al}_{7} \mathrm{Nb}$ alloy showed a more grainy appearance and contained calcium titanate precipitates. Simulated Body Fluid (SBF) and cell culture tests were conducted to compare the biological performance of the alloys. Even though oxidized alloys exhibited somewhat similar response in SBF tests, the number of 
SAOS-2 cells attached to the oxide layer of the Ti6Al4V alloy was greater than that of the $\mathrm{Ti}_{6} \mathrm{Al}_{7} \mathrm{Nb}$ alloy.

2. 'Plasma Electrolytic Oxidation (PEO) for production of anodized coatings on lightweight' worked by Walsh et al [2]. The introduction of Plasma Electrolytic Oxidation (PEO) as a surface finishing technique has enabled a range of hard, dense oxide coatings to be produced on aluminum, magnesium, titanium and other lightweight alloy substrates. As with all surface coating technologies, successful development of PEO coatings requires adequate attention to substrate pretreatment together with careful control of electrolyte conditions and process variables. The principles and applications of the PEO coating process are considered, including the fundamentals of oxide deposition, the technology involved and the typical characteristics of the coatings. Industrial applications are considered together with their coating requirements. Plasma electrolytic oxidation coating is a specialized but well developed process. Suitable control of electrolyte and process conditions can realize a novel range of coatings having technologically attractive physical and chemical properties. The development of PEO technology over the last decade has provided coatings having controlled appearance, hardness, corrosion resistance and other tribological properties across an extending range of industrial sectors. Continuing developments are concisely reviewed and the PEO process is illustrated by the characterization of anodized coatings on an AZ91 magnesium alloy surface.

3. 'Effect of Micro Arc Oxidation Treatment Time on In-Vitro Corrosion Characteristics of Titania Films on CP Ti' worked by K. Venkateswarlu et al

The work is aimed at the optimization of treatment time for the development of an oxide film on commercially pure titanium (CP Ti) implant material by Micro Arc Oxidation (MAO) process, to improve its corrosion resistance under $7.4 \mathrm{pH}$ simulated body fluid physiological conditions. The MAO treatments were conducted for 4,8 and 12 min in constant current mode by a DC power supply unit with an aqueous electrolyte solution comprising 15 $\mathrm{g} / \mathrm{l}$ of tri-sodium ortho phosphate $\left(\mathrm{Na}_{3} \mathrm{PO}_{4} \cdot 12 \mathrm{H}_{2} \mathrm{O}\right)$. The phase composition of the fabricated films was analyzed by X-Ray Diffraction (XRD) technique. The morphology and thickness of the films were determined by Scanning Electron Microscopy (SEM) and the corrosion characteristics were assessed by potentio dynamic polarization technique. The XRD results demonstrated that the oxide films mainly consisted of anatase phase. While the average size of isolated surface pores was in the range of 0.5 to $5 \mu \mathrm{m}$, the thickness of the film varied from 24 to $55 \mu \mathrm{m}$. A significant improvement in the corrosion resistance was observed for the MAO treated $\mathrm{CP}$ Ti implant material compared to that of the untreated. The surface pore features, the thickness of the film and the corrosion characteristics of the developed films were correlated with the MAO treatment time. Of the three different MAO treatment times employed in the present study, 8 min treatment time was established to be an optimized one for developing oxide films on $\mathrm{CP}$ $\mathrm{Ti}$ to provide an optimal surface porosity and to minimize corrosion rate under physiological conditions.

\section{MATERIALS AND METHODOLOGY:} PROCESS FLOW DIAGRAM

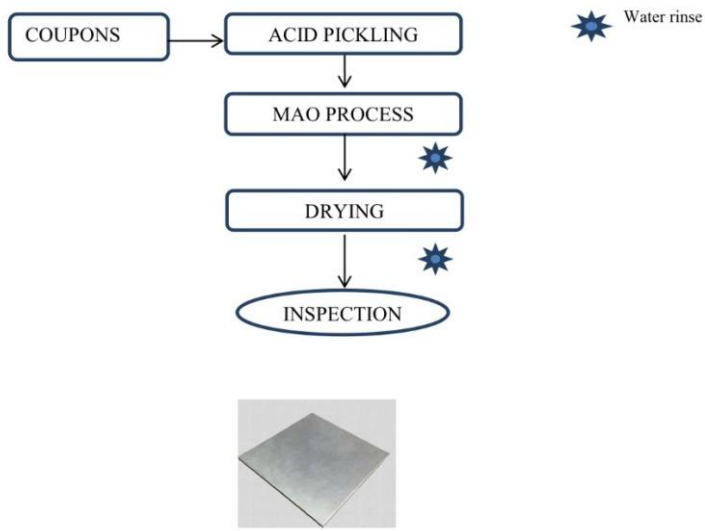

Fig 1: Bare sample without coating

A typical treatment unit for MAO processing consists of a processing tank, cooling unit, agitator and a high power electrical source as shown in Fig.2

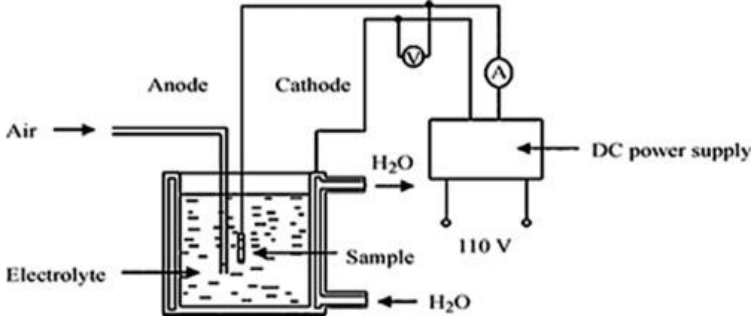

Fig.2: A schematic representation of typical treatment unit for MAO processing

A PP processing tank $(40 \mathrm{~cm} \mathrm{X} 30 \mathrm{~cm} \mathrm{X} 30$ $\mathrm{cm}$ ) having a capacity of 20 liters is connected to a cooling system and high voltage power supply along with an air circulation unit for continuous agitation 
of the electrolyte. The processing tank is equipped with a stainless steel sheet which acts as cathode during the process of MAO.

\section{A. Sample preparation:}

$\mathrm{Ti}_{4} \mathrm{Al}_{4} V$ sheet was cut into square pieces of dimension $4 \mathrm{~cm} \mathrm{X} 4 \mathrm{~cm} \mathrm{X} \mathrm{1mm.} 2$ holes of diameter $1 \mathrm{~mm}$ were drilled at the edges of the sample. The irregular spurs along the cut edges and drilled holes of the square pieces were eliminated by abrasive equipment. The samples were jigged using aluminum wire.

Pre-treatment techniques: Although pretreatments are not necessary for the substrate, degreasing and/or acid cleaning were done to ensure a clean and active surface to start with.

Degreasing: The samples were degreased using Methyl-ethyl ketone in an ultra-sonicatorfor 510 minutes at a temperature of $25 \pm 5$ degrees centigrade.

Acid pickling Solution:

Nitric acid $(70 \%)-262.5 \mathrm{ml} / \mathrm{l} \quad$ Hydrofluoric acid $(40 \%)-225 \mathrm{ml} / \mathrm{l}$

The substrate was cleaned in the above solution for 1 to 2 minutes at a temperature of $25 \pm 5$ degrees centigrade. After cleaning, the sample was rinsed thoroughly with fresh water followed by D M water.

\section{B. MAO process:}

All the samples were connected as anodes and a stainless steel plate was used as cathode to complete the circuit. Appropriate electrolytes were used for the process. A detailed explanation of electrolyte selection is given under Results and Discussion. Air sparger was used to agitate the electrolyte by bubbling air through 20 liters of electrolyte to maintain uniform composition throughout. The electrolyte bath was maintained at $25 \pm 5$ degrees centigrade with cooling circulation bath. MAO of the specimen was carried out at constant current mode. The sample was immersed in the solution and the firm electrical connections were made to AC power supply. The processing parameters like duty cycle, current density, frequency, on time and off time were selected. The process was performed until the set processing time is reached, after which, it was removed from the solution and rinsed with demineralized water. The sample was again dried using hot air gun.

TESTS: The evaluation of the coatings was done using thickness meter, emissometer and reflectometer.

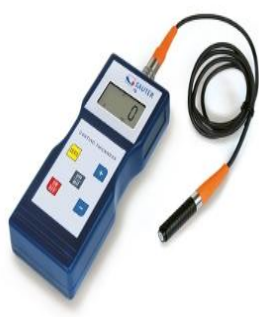

Thickness meter

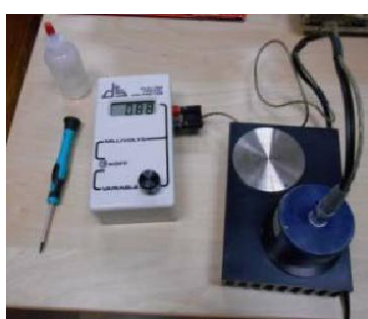

Emissometer

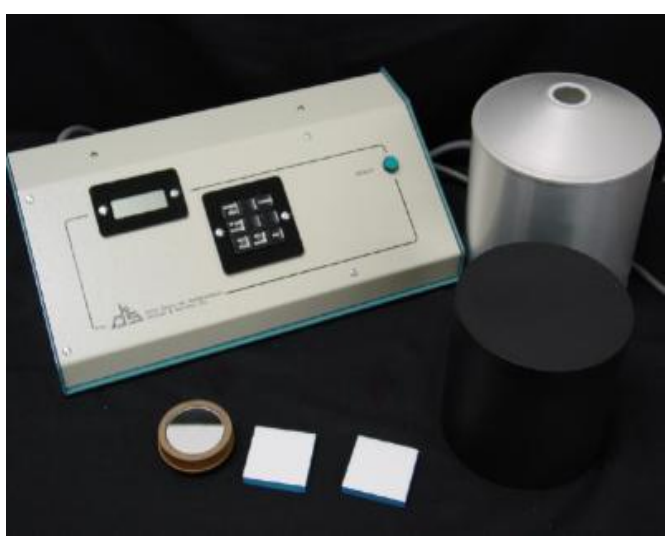

Reflectometer

\section{RESULTS AND DISCUSSION}

The project pre-dominantly involves determination of two important parameters: electrolyte composition and current density

\section{A. Electrolyte selection}

Several electrolytes picked up randomly from literature were utilized for the development of oxide layer on titanium alloy. The thickness, emissivity and absorptivity of the resultant coatings were analyzed. The selection of the appropriate electrolyte was not only based on the higher value of emittance but also on the appearance and uniformity of the coating.

General process parameters employed for the present study are as follows:

Frequency: $50 \mathrm{~Hz}$

On-time (+ve): $700 \mu \mathrm{s}$

Average current density (+ve): 15, 25 and 50 ASF

(Ampere per sq. feet)

Processing time: 15, 30, 45, $60 \mathrm{~min}$

Temperature: $25 \pm 5$ degrees centigrade

\section{Solution1:}

Initially, a silicate and phosphate based aqueous electrolyte was selected for the process.

The process was done at an average current density of 50 ASF for $15 \mathrm{~min}$. The solution composition and thermos-optical properties obtained for the corresponding coating is consolidated in Table 1 . 
With increase in concentration of phosphate in the electrolyte the thickness of the coating was increasing and there was a corresponding increase in the emissivity. The coating obtained with $15 \mathrm{~g} / \mathrm{l}$ of phosphate gave a high emittance value of 0.83 . However, the coating roughness was high and the coating obtained was non uniform and patchy, especially at the edges. Hence, this electrolyte was not considered for further studies.

Table 1: Solution composition and corresponding thickness and thermo-optical properties

\begin{tabular}{|c|c|c|c|c|c|c|}
\hline Sample No & SS & NaOH & TSOP & Thickness & Absorptivity & Emissivity \\
\hline & $\mathrm{g} / \mathrm{l}$ & $\mathrm{g} / \mathrm{l}$ & $\mathrm{g} / \mathrm{l}$ & $\mu \mathrm{m}$ & $\alpha$ & $\varepsilon$ \\
\hline 1 & 15 & 2 & 0 & 6 & 0.826 & 0.8 \\
\hline 2 & 15 & 2 & 5 & 7 & 0.823 & 0.81 \\
\hline 3 & 15 & 2 & 10 & 13 & 0.829 & 0.82 \\
\hline 4 & 15 & 2 & 15 & 20 & 0.832 & 0.83 \\
\hline
\end{tabular}

Where SS - Sodium Silicate; TSOP - Tri-Sodium Orthophosphate;

\section{Solution2:}

In the second set of trials, again a silicatephosphate electrolyte was chosen in which the concentration of tri-sodium orthophosphate remained constant while the concentration of sodium silicate was increased in steps of $5 \mathrm{~g} / \mathrm{l}$. The process was done at an average current density of $50 \mathrm{ASF}$ for $15 \mathrm{~min}$. The solution composition and thermosoptical properties obtained for the corresponding coating is consolidated in Table 2 .

This electrolyte gave well finished and uniform coating on the substrate, while the thickness and roughness increased in proportion to the concentration of aluminates. Also, the emissivity did not increase significantly with the thickness. Thus, this solution was excluded from further studies.
Table 2: Solution composition and corresponding thickness and thermo-optical properties

\begin{tabular}{|c|c|c|c|c|c|c|}
\hline Sample No & SS & NaOH & TSOP & Thickness & Absorptivity & Emissivity \\
\hline & $\mathrm{g} / \mathrm{l}$ & $\mathrm{g} / \mathrm{l}$ & $\mathrm{g} / \mathrm{l}$ & $\mu \mathrm{m}$ & $\alpha$ & $\varepsilon$ \\
\hline 1 & 15 & 2 & 15 & 20 & 0.831 & 0.82 \\
\hline 2 & 20 & 2 & 15 & 25 & 0.832 & 0.82 \\
\hline 3 & 25 & 2 & 15 & 30 & 0.85 & 0.83 \\
\hline 4 & 30 & 2 & 15 & 30 & 0.876 & 0.83 \\
\hline
\end{tabular}

\section{Solution3:}

The effect of concentration of phosphate on the roughness was studied by adding Tri-sodium orthophosphate to a solution having high concentration of silicate $(30 \mathrm{~g} / \mathrm{l})$ and a very low concentration of sodium hydroxide $(2 \mathrm{~g} / \mathrm{l})$ in increments of $5 \mathrm{~g} / \mathrm{l}$. The process was carried out for 15 minutes using an average current density of 15ASF. The solution composition and thermo optical properties obtained for the corresponding coating is consolidated in Table 3 .

A similar effect was observed i.e. roughness increased with the concentration of phosphate. Thus, the electrolyte was rejected.

Table 3: Solution composition and corresponding thickness and thermo-optical properties

\begin{tabular}{|c|c|c|c|c|c|c|}
\hline Sample No & $\mathrm{SS}$ & $\mathrm{NaOH}$ & $\mathrm{TSOP}$ & Thickness & Absorptivity & Emissivity \\
\hline & $\mathrm{g} / \mathrm{g} / \mathrm{g}$ & $\mathrm{g} / \mathrm{l}$ & $\mu \mathrm{m}$ & $\alpha$ & $\varepsilon$ \\
\hline 1 & 30 & 2 & 0 & 10 & 0.841 & 0.77 \\
\hline 2 & 30 & 2 & 5 & 9 & 0.835 & 0.78 \\
\hline 3 & 30 & 2 & 10 & 15 & 0.852 & 0.79 \\
\hline 4 & 30 & 2 & 15 & 27 & 0.876 & 0.83 \\
\hline
\end{tabular}




\section{Solution4:}

Introduction of small quantity of potassium fluoride to the electrolytic solution decreases the roughness of the surface of coating. So, to evaluate the effect of KF, the process was carried out for a processing time of 15 minutes at an average current density of 15 ASF. The solution composition and thermo optical properties obtained for the corresponding coating is consolidated in Table 4 .

Table 4: Solution composition and corresponding thickness and thermo-optical properties

\begin{tabular}{|c|c|c|c|c|c|c|}
\hline Sample No & SS & TSOP & KF & Thickness & Absorptivity & Emissivity \\
\hline & $\mathrm{g} / \mathrm{l}$ & $\mathrm{g} / \mathrm{l}$ & $\mathrm{g} / \mathrm{l}$ & $\mu \mathrm{m}$ & $\alpha$ & $\mathrm{E}$ \\
\hline 1 & 30 & 0 & 0 & 6 & 0.825 & 0.76 \\
\hline 2 & 30 & 0 & 1 & 8 & 0.824 & 0.77 \\
\hline 3 & 30 & 5 & 1 & 10 & 0.835 & 0.79 \\
\hline 4 & 30 & 10 & 1 & 15 & 0.836 & 0.81 \\
\hline
\end{tabular}

The addition of potassium fluoride to the solution did not vary the surface characteristics of the coatings, greatly. It can also be observed that the addition of potassium fluoride has decreased the coating rate, thickness and emissivity. Considering the above negative impacts on the coating, the solution was omitted from further studies. The above silicate-phosphate based solution did not provide the desired coating characteristics on the substrate. Thus, the electrolytic solution constituents were changed.

\section{Solution5:}

An Aluminate and phosphate based aqueous electrolyte was chosen to study its effect on the coating. The concentrations of both aluminate and phosphate were varied simultaneously during the process carried at an average current density of 15 ASF for 60 minutes. The solution composition and thermo optical properties obtained for the corresponding coating is consolidated in Table 5.
Table 5: Solution composition and corresponding thickness and thermo-optical properties

\begin{tabular}{|c|c|c|c|c|c|}
\hline Sample No & TSOP & S A & Thickness & Absorptivity & Emissivity \\
\hline & $\mathrm{g} / 1$ & $\mathrm{~g} / 1$ & $\mu \mathrm{m}$ & $\alpha$ & $\varepsilon$ \\
\hline 1 & 5 & 5 & 4 & 0.64 & 0.66 \\
\hline 2 & 5 & 10 & 4 & 0.642 & 0.66 \\
\hline 3 & 5 & 15 & 5 & 0.653 & 0.67 \\
\hline 4 & 10 & 15 & 7 & 0.668 & 0.7 \\
\hline 5 & 15 & 15 & 8 & 0.673 & 0.71 \\
\hline 6 & 25 & 15 & 10 & 0.713 & 0.73 \\
\hline 7 & 25 & 25 & 12 & 0.731 & 0.75 \\
\hline 8 & 35 & 25 & 15 & 0.757 & 0.77 \\
\hline 9 & 35 & 35 & 17 & 0.77 & 0.78 \\
\hline 10 & 45 & 35 & 22 & 0.798 & 0.81 \\
\hline 11 & 45 & 45 & 30 & 0.826 & 0.84 \\
\hline 12 & 50 & 45 & 35 & 0.818 & 0.85 \\
\hline
\end{tabular}

It can be observed from Table 5 that the concentration of electrolyte has direct influence on the thickness and emissivity of the coatings. Also, from visual observation, it was noticed that the samples were grey-colored, uniform and smooth. It had developed uneven edges and the coating was not uniform.

The sample treated in an electrolyte having composition 45g/l Sodium Aluminate and 50g/l Trisodium orthophosphate at a current density of 15 ASF gave desirable parameters like:

Thickness: $35 \mu \mathrm{m}$;

Emissivity: 0.85;

Appearance: smooth, well finished and uniform. Thus, the electrolyte composition was finalized.

\section{CONCLUSION}

1. A sample(shown in table 5, sample 12) treated at room temperature ( $25 \pm 50$ degrees centigrade) using $45 \mathrm{~g} / \mathrm{l}$ Sodium aluminate, $50 \mathrm{~g} / \mathrm{l}$ Tri-sodium orthophosphate and $2 \mathrm{~g} / \mathrm{l}$ Cobalt acetate (additive) at an average current density of 15 ASF for 60 minutes gave a high emissivity value of 0.85 and absorbance of 0.818 .

2. The emissivity of the coating is influenced by coating thickness, current density, frequency, voltage applied, processing time, additives and temperature of the electrolyte.

3. The coatings have excellent interfacial adhesion. 


\section{REFERENCE}

[1]. 'Micro-arc oxidation of Ti6Al4V and Ti6Al7Nb alloys for biomedical applications' by Huseyin CimenogluMert GunyuzGamze Torun KoseMurat CES.

[2]. 'Plasma electrolytic oxidation (PEO) for production of anodised coatings on lightweight' by Walsh, F.C., Low, C.T.J., Wood, R.J.K., Stevens, K.T., Archer, J., Poeton, A.R. and Ryder.

[3]. 'Effect of Micro Arc Oxidation Treatment Time on In-Vitro Corrosion Characteristics of Titania Films on $\mathrm{Cp}$ Ti' by $\mathrm{K}$. Venkateswarlu, J. Hari, D. Sreekanth, M. Sandhyarani, A. C. Bose, and N. Rameshbabu.

[4]. B. N. Agarwal: „Design of geosynchronous spacecrafts", 241; 1986, Englewood, NJ, Prentice Hall.

[5]. James A curran, Peterhouse "Thermal \& mechanical properties of plasma electrolytic oxide coatings", a research thesis, University of Cambridge, Dept. of Material science and Metallurgy, 2005

[6]. Allan Mathews et al., Novel plasma treatment processes to improve the wear and corrosion performance of light alloys", from EPSRC grant no GR/F15696

[7]. Yerokhin, A. L, X Nie, A Leyland, A Matthews and S J Dowey, Plasma electrolysis for Surface engineering (Review). Surf.Coat.Techn., 1999. 122(23): p.73-93

[8]. Khaselev, O, D Weiss, and J Yahalom, Anodising of pure Magnesiums in KOHAluminate Solutions under sparking. J Electrochem. Soc., 1999. 146(5): p.17571761

[9]. Mc Neil, W and L LGruss, U S Patent 3,293,158 Anodic spark reaction processes and articles. 1966: USA

[10]. Bonilla, F A, A Berkani, Y Liu, P Skeldn, g E Thompson, H Habazadi, K Shimizu, C John and K Stevens, Formation of anodic films on magnesium alloys in an alkaline phosphate electrolyte. J Electrochem. Soc., 2002. 149 (1): p. B4-B13

[11]. Li JZ, Shao ZC, Tian YW, Kang FD, Zhai YC. Application of microarc oxidation for $\mathrm{Al} 、 \mathrm{Mg}, \mathrm{Ti}$ and their alloys, Corrosion Science and Protection Technology 2004; 16(4): 218-221

[12]. Shin KR, Ko YG, Shin DH. Effect of electrolyte on surface properties of pure titanium coated by plasma electrolytic oxidation, Journal of Alloys and Compounds 2011; 509: s478-s481
[13]. Becerik DA, Ayday A, Kumruoğlu LC, Kurnaz SC, Özel A. The Effects of $\mathrm{Na} 2 \mathrm{SiO} 3$ Concentration on the Properties of Plasma Electrolytic Oxidation Coatings on 6060 Aluminum Alloy, JMEPEG 2012; 21:1426-1430.

[14]. Forno AD, Bestetti M. Effect of the electrolytic solution composition on the performance of micro-arc anodic oxidation films formed on AM60B magnesium alloy, Surface and Coatings Technology 2010; 205: 1783-1788.

[15]. Shi XL, Wang QL, Wang FS, Ge SR, Effects of electrolytic concentration on properties of micro-arc film on Ti6Al4V alloy, Mining Science and Technology 2009; 19: 220- 224

[16]. Wei CB, Tian XB, Yang SQ, Wang XB, Fu RKY, Chu PK. Anode current effects in plasma electrolytic oxidation, Surface and Coatings Technology 2007; 201: 50215024 .

[17]. Hussein RO, Nie X, Northwood DO. Influence of process parameters on electrolyticplasma discharging behaviour and aluminum oxide coating microstructure, Surface and Coatings Technology 2010; 205: 1659-1667.

[18]. Yang Y, Wu H. Effects of Current Frequency on the Microstructure and Wear Resistance of Ceramic Coatings Embedded with $\mathrm{SiC}$ Nano-particles Produced by Micro-arc Oxidation on AZ91D Magnesium Alloy, Journal of Material Science Technology 2010; 26(10): 865871.

[19]. Khan RHU, Yerokhin A, Li X, Dong H, Matthews A. Surface characterisation of DC plasma electrolytic oxidation treated 6082 aluminium alloy: Effect of current density and electrolyte concentration, Surface and Coatings Technology 2010; 205: 1679-1688.

[20]. Huang P, Wang F, Xu KW, Han Y. Mechanical properties of titania prepared by plasma electrolytic oxidation at different voltages, Surface and Coatings Technology 2007; 201: 5168-5171.

[21]. Liu F, Xu JL, Yu DZ, Wang FP, Zhao LC. Effects of cathodic voltages on the structure and properties of ceramic coatings formed on NiTi alloy by micro-arc oxidation, Materials Chemistry and Physics 2010; 121: 172-177.

[22]. Tang YM, Zhao XH, Jiang KS, Chen J, Zuo $Y$. The influences of duty cycle on the 
[23]. bonding strength of AZ31B magnesium alloy by microarc oxidation treatment, Surface and Coatings Technology 2010; 205: 1789-1792.

[24]. Habazaki H, Tsunekawa S, Tsuji E, Nakayama T. Formation and characterization of wear-resistant PEO coatings formed on $\beta$-titanium alloy at different electrolyte temperatures,Applied Surface Science 2012; 259: 711-718.

[25]. Gu YH, Bandopadhyay S, Chen CF, Guo YJ, Ning CY. Effect of oxidation time on the corrosion behavior of micro-arc oxidation produced AZ31 magnesium alloys in simulated body fluid, Journal of Alloys and Compounds 2012; 543: 109 117.

[26]. Hui Tang, Q Sun, C G Yi, F P Wang, High emissive coating on titanium alloy for micro arc oxidation for high temperature application

[27]. Selim kaan Yazici, Faiz Muhaffel, Murat Baydogan. Effect of incorporating carbon nanotubes into electrolyte on surface morphology of micro-arc oxidized $\mathrm{Cp}$ Ti,Applied surface science 318(204) 10-14

[28]. K Venkateswarulu, J Hari, D sreekanth, M Sandhyarani, A C Bose, N Rameshbabu.Effect of Micro arc oxidation treatment time on in-vitro corrosion characteristics of Titanium films on $\mathrm{Cp}-\mathrm{Ti}$, International Journel of io-science and Bioinformatics, Vol 2 No 6, November 2012.

International Journal of Engineering Research and Applications (IJERA) is UGC approved Journal with Sl. No. 4525, Journal no. 47088. Indexed in Cross Ref, Index Copernicus (ICV 80.82), NASA, Ads, Researcher Id Thomson Reuters, DOAJ.

Deepa H A. "Optimization of Suitable Electrolyte for High Emittance coating on Titanium Alloy." International Journal of Engineering Research and Applications (IJERA) 7.7 (2017): 93-99. 